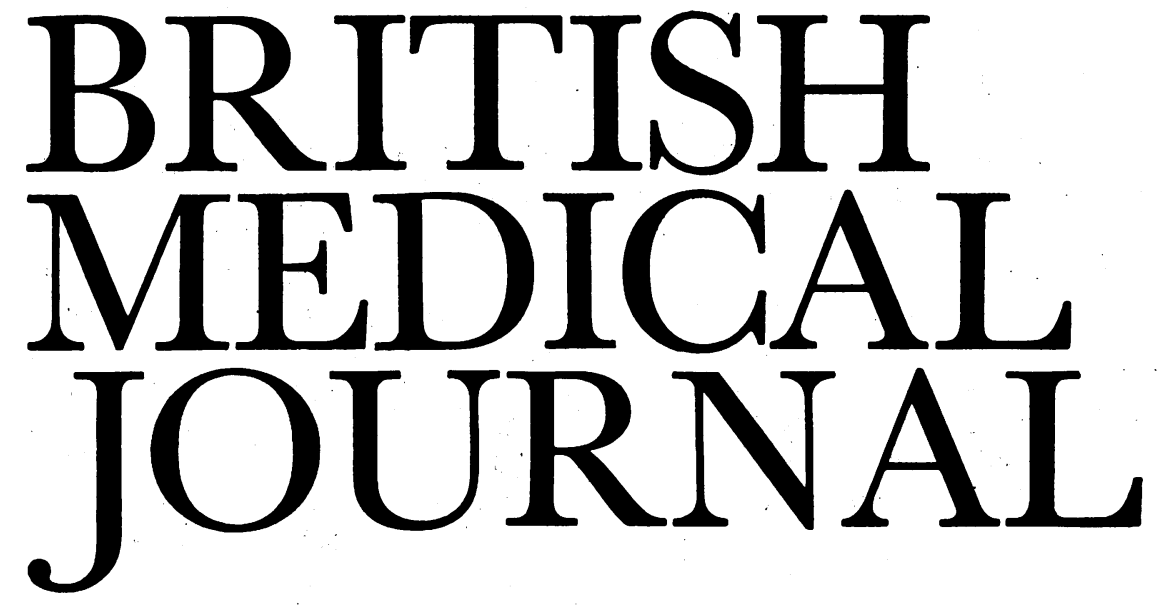

LONDON, SATURDAY 25 JULY 1987

\title{
The myelodysplastic syndromes
}

The concept of preleukaemia originated early in this century with the recognition of prodromal haematological abnormalities in acute myeloid leukaemia. ${ }^{1}$ Since then similar preleukaemic disorders have been described, including primary acquired sideroblastic anaemia and smouldering or oligoblastic leukaemia. Confusion created by differing connotations placed on the term preleukaemia was resolved in 1982 by the introduction of a common nomenclature based on morphological criteria. Under the generic term of myelodysplastic syndromes five subgroups were defined: refractory anaemia; refractory anaemia with ring sideroblasts; refractory anaemia with an excess of blasts; refractory anaemia with an excess of blasts in transformation; and chronic myelomonocytic leukaemia. ${ }^{2}$ Other conditions associated with a risk of developing acute myeloid leukaemia such as aplastic anaemia, paroxysmal nocturnal haemoglobinuria, Down's syndrome, and chromosomal breakage syndromes are excluded.

Though the myelodysplastic syndromes occur mainly in the elderly; they have been increasingly recognised in younger patients, including children, ${ }^{3}$ and after chemotherapy or radiotherapy for malignant and non-malignant disease. ${ }^{4}$ Cytopenia is a dominant feature, most patients presenting with anaemia, infection, bruising, or haemorrhage. The liver and the spleen may be enlarged, though not strikingly so except in chronic myelomonocytic leukaemia, where hypertrophy of the gums, infiltrative skin lesions, lymphadenopathy, and, rarely, serous effusions also occur. ${ }^{56}$ Typically there is a combination of anaemia, neutropenia, and thrombocytopenia, though in chronic myelomonocytic leukaemia there is a characteristic monocytosis and neutrophilia. Anaemia, usually macrocytic despite the absence of vitamin $B_{12}$ or folic acid deficiency, is accompanied by a range of red cell abnormalities and hyposegmented (pseudoPelger) hypogranular neutrophils. The bone marrow reflects ineffective haemopoiesis and shows characteristic morphological abnormalities of all cell lines. These features are mirrored by functional defects of the neutrophils and platelets, which contribute to the risk of infection and bleeding. ${ }^{78} \mathrm{~A}$ variety of non-specific epiphenomena occur, including quantitative red cell enzyme abnormalities, low neutrophil alkaline phosphatase activity, raised fetal haemoglobin concentrations, altered expression of blood group antigens, and, rarely, a positive Ham's test. Serum and urinary lysozyme activities are raised in chronic myelomonocytic leukaemia.

Non-random chromosome abnormalities occur in up to $79 \%$ of cases. ${ }^{9}$ Some of these have specific clinical correlations. For example, deletion of the long arm (q) of chromosome 5 is associated with a syndrome seen mainly in elderly women characterised by macrocytic anaemia, a normal or high platelet count, and long survival. ${ }^{10}$

Recently myelodysplastic syndromes have been shown to coexist on occasions with proliferative disorders of $\mathrm{B}$ or T lymphoid cells, perhaps indicating involvement of a stem cell with capacity for both lymphoid and myeloid differentiation. ${ }^{11}$ An increased incidence of non-haematological malignancy has also been observed (A Jacobs, personal communication). Whether this reflects impaired tumour surveillance due to associated immune defects ${ }^{12}$ or a hereditary or environmental predisposition is uncertain.

Though patients with myelodysplastic syndromes may survive for many years, over half die within one year of diagnosis, marrow failure being a more common cause of death than transformation to acute myeloid leukaemia, which occurs in just under a third of cases. Patients with refractory anaemia and refractory anaemia with ring sideroblasts fare better than those with chronic myelomonocytic leukaemia, refractory anaemia with an excess of blasts, and refractory anaemia with an excess of blasts in transformation, where progressively shorter survival is related to the increasing risk of leukaemic transformation. ${ }^{14}$ Patients whose disease follows an indolent course require no treatment or only intermittent red cell transfusion. Younger patients with refractory anaemia with an excess of blasts, refractory anaemia with an excess of blasts in transformation, and chronic myelomonocytic leukaemia may benefit from combination chemotherapy ${ }^{1516}$ or allogeneic bone marrow transplantation. ${ }^{17}$ For other patients, who are mostly elderly, treatment with isotretinoin, a vitamin A metabolite, or cytarabine has been proposed. These agents were introduced after the observation that they induce differentiation in vitro of myeloid leukaemia lines. ${ }^{1819}$ Results have been encouraging. Over a third of 97 patients treated with low dose cytarabine showed a response.$^{20}$ Experience with isotretinoin is more limited.

To answer questions about duration of treatment and impact on survival the Medical Research Council has set up a 
trial comparing the efficacy of subcutaneous low dose cytarabine alone or in combination with isotretinoin versus supportive treatment alone. The therapeutic potential of interferons, haemopoietic growth factors, and other biological response modifiers is currently being evaluated. Preliminary results suggest that these may provide a novel strategy for treating myelodysplastic syndromes.

D M LAYTON Sir John Dacie fellow

G J MUFTI

Senior lecturer

Department of Haematology,

King's College School of Medicine

and Dentistry,

London SE5 8RX

1 Parkes-Weber F. A case of leukanaemia. Transactions of the Pathological Society of London 1904;55:288-96.

2 Bennett JM, Catovsky D, Daniel M-T, et al. The French-American-British cooperative group Proposals for the classification of the myelodysplastic syndromes. Br $\mathcal{F}$ Haematol 1982;51 $189-99$.

3 Wegelius R. Preleukaemic states in children. Scand J Haematol [Suppl] 1986;36:133-9.

4 Michels SD, McKenna RW, Arthur DC, Brunning RD. Therapy related acute myeloid leukemia and myelodysplastic syndrome: a clinical and morphological study of 65 cases. Blood 1986;65:1364-72.

5 Mufti GJ, Oscier DG, Hamblin TJ, Nightingale A, Darlow S. Serous effusions in monocytic leukaemias. Br $\mathcal{F}$ Haematol 1984:58:547-52.

6 Duguid JKM, Mackie MJ, McVerry BA. Skin infiltration associated with chronic myelomonocytic leukaemia. Br $\mathcal{H}$ Haematol 1983;53:257-64.

monocytic leukaemia. Br Foematol $1983 ; 53: 257-64$.
Boogaerts MA, Nelissen V, Roelant C, Goossens W. Blood neutrophil function in primary myelodysplastic syndromes. Br $\mathcal{I}$ Haematol 1983;55:217-27.

8 Lintula R, Rasi V, Ikkala E, Bergstrom GH, Vuopio P. Platelet function in preleukaemia. Scand $\mathcal{J}$ Haematol 1981;96:65-71.

9 Yunis JJ, Rydell RE, Oken MM, Arneson MA, Mayer MG, Lobell M. Refined chromosomal analysis as an independent prognostic indicator in de novo myelodysplastic syndromes. Bloo 1986;67:1721-30.

10 Van den Berghe H. The Sq- syndrome. Scand J Haematol [Suppl] 1986;36:78-81

11 Copplestone JA, Mufti GJ, Hamblin TJ, Oscier DG. Immunological abnormalities in myelodysplastic syndromes. II. Coexistent lymphoid or plasma cell neoplasms: a report of 20 cases unrelated to chemotherapy. Br f Haematol 1986;63:149-59.

12 Bynoe AG, Scott CS, Ford P, Roberts BE. Decreased T-helper cells in the myelodysplastic syndromes. BrF Haematol 1983;54:97-102.

13 Kerndrup G, Mayer K, Ellegard J, Hokland P. Natural killer (NK) activity and antibody dependent cellular cytotoxicity (ADCC) in primary preleukemia syndrome. Leuk Res 1984;8: $239-47$.

14 Mufti GJ, Galton DAG. Myelodysplastic syndromes: natural history and features of prognostic importance. Clin Haematol 1986;15:953-71.

15 Mertelsmann R, Thaler HT, To L, et al. Morphological classification, response to therapy and survival in 263 adult patients with acute non-lymphocytic leukemia. Blood 1980;56:773-81.

16 Armitage JO, Dick FR, Needleman SW, Burns CP. Effect of chemotherapy for the dysmyelopoietic syndrome. Cancer Treat Rep 1981;65:601-5.

17 Appelbaum FR, Storb R, Ramberg RE, et al, Allogeneic marrow transplantation in the treatment of preleukemia. Ann Intern Med 1984;100:689-93.

18 Breitman TE, Selonick SE, Collins SJ. Induction of differentiation of the human promyelocytic leukemia cell line (HL60) by retinoic acid. Proc Natl Acad Sci USA 1980;77:2936-40.

19 Griffin J, Munroe D, Major P, Kufe D. Induction of differentiation of human myeloid leukemia cells by inhibitors of DNA synthesis. Exp Hematol 1982;10:774-81.

20 Mufti GJ, Oscier DG, Hamblin TJ. Low dose cytarabine (Ara-C) in the treatment of myelodysplastic syndromes (MDS) and acute myeloid leukaemia (AML). Brf Haematol 1985;61:571.

\section{The psychiatry of HIV infection}

All the various forms of infection with the human immunodeficiency virus (HIV) can have an important psychological impact..$^{1-3}$ Indeed, psychological problems are also seen in those uninfected but anxious that they might be-the "worried well." The recent international conference on the acquired immune deficiency syndrome (AIDS) discussed all the psychological problems that may be associated with HIV infection (third international AIDS conference, Washington DC, June 1987).

HIV may cause a presenile dementia called the AIDS dementia complex. ${ }^{4}$ The typical features are motor slowing, poor concentration, and memory loss. Most patients deteriorate steadily, but in about a fifth the disease runs an indolent course. At its most advanced the dementia may be severe, with mutism, incontinence, paraplegia, and myoclonus." At the conference $\mathrm{Dr} R$ Vazeuz and her colleagues described how they localised HIV proteins in the brains of patients with AIDS to macrophages normally resident in the brain and not to neurones or astrocytes.

A battery of neuropsychological tests on over 180 patients with AIDS followed up for three years showed that half developed important cognitive impairment (S Tross et al, AIDS conference, Atlanta, Georgia, 1985). These tests are, however, time consuming to use, and a new development is a brief clinically orientated battery that correlates well with a more exhaustive one (J J Sidtis $e t a l$ ). It has been used to confirm that the more severe the somatic infection with HIV the worse the cognitive dysfunction.

Patients infected with HIV selected from an American cohort of 5000 homosexuals showed widespread minor abnormalities in cognitive function, but only $2 \%$ had early AIDS dementia complex (J C McArthur et al). A smaller study (I Grant et al) found that as many as $44 \%$ of otherwise asymptomatic subjects had appreciable cognitive impairment (compared with $9 \%$ of healthy uninfected gay men, $54 \%$ of patients with AIDS related complex, and $87 \%$ of patients with AIDS). In another study half the patients with î polyglandular lymphodenopathy had evidence of cognitive or impairment and peripheral neurological disorders ( $R S$ Janssen $e t a l$ ).

The commonest reasons for referring patients with AIDS N to a liaison psychiatry service were depression $(16 \%)$, suicidal $\mathrm{O}$ ideation (16\%), and treatment refusal $(7 \%)$. Other reasons for referral were agitation, anxiety, and inability to cope. A o quarter were diagnosed as having adjustment disordersprolonged maladaptive reactions causing appreciable social $\_$ impairment - and a quarter had organic brain syndromes $\left(H_{\infty}\right.$ $\mathrm{W}$ Weisman et $a l$ ). Adjustment disorders have been found in $60 \%$ of those with AIDS related complex, $41 \%$ of those with AIDS, and $23 \%$ of asymptomatic but infected patients. Major depression is less common (occurring in $15 \%$ of those with AIDS related complex, $13 \%$ of those with AIDS, and $5 \%$ of those who are asymptomatic) and generalised anxiety disorder rare (occurring in 15\% of those with AIDS related complex, none of those with AIDS, and $5 \%$ of those who are asymptomatic) (S Tross et al). Severe depression may have an organic component, and treatment with antidepressant drugs may thus not be effective; the drugs, particularly those with anticholinergic effects, may precipitate confusional states. ${ }^{5-7}$

At the conference Dr D Miller showed that many patients 0 - the worried well-had presented because of the publicity surrounding AIDS. They are similar to patients with syphilis $ᄋ$ phobia and are obsessional and rigid and have never had $N$ sexually transmitted diseases. They misinterpret various $\rightarrow$ somatic complaints, have many tests without relief of anxiety, and demand frequent reassurance from the doctor. $N$ Their anxiety is difficult to allay, and they may develop $\underset{\mathrm{C}}{\mathrm{N}}$ persistent and refractory depressions.

Health workers may need to confront their own prejudices towards the high risk groups in order to offer the highest $\mathbb{\Phi}$ standard of care.$^{8-10}$ Doctors' responses to four nearly identical $\stackrel{?}{+}$ case vignettes depended on whether the patient described $\frac{0}{\circ}$ had AIDS or leukaemia and was either homosexual or heterosexual (J S St Lawrence et $a$ ) : doctors believed that homosexual patients with AIDS deserved their diagnoses and were less deserving of the doctor's sympathy.

We are only just learning about the consequences of HIV infection on human behaviour, and the psychiatric

\section{管}

